\title{
Global Journal of Mechanical Sciences and Engineering
}

(ISSN:2692-1324)

\section{The influence of the stratum structure of the pipe pile sliding pile of the offshore platform}

\section{Hongru Li}

Shanghai Maritime University, Shanghai 201306, China.

\begin{abstract}
This article has carried on the theoretical analysis to the foundation meets the design requirgeneration mechanism of the sliding pile phenomenon. A certain ements.

prediction was made on the causes of slipping piles and their Keywords: Slipped pile; Stratum sinfluencing factors. At the same time, it is based on the collected tructure; Numerical Simulation; Pile field measurement data, an engineering example is selected foundation bearing capacity to briefly analyze the changes in the bearing capacity of the pile foundation after the sliding pile occurs. It is found that the influence of the sliding pile on the bearing capacity of the pile foundation is mainly the influence on the side friction resistance of the pile, and the reduction of the soil resistance is also mainly due to the reduction of the side friction resistance of the pile. Finally, using ABAQUS finite element analysis software, a numerical simulation analysis was carried out on the changes of the stratum structure, the analysis results show that the position change of the soft soil layer has a certain influence on the bearing capacity of the pile, but it does not change the settlement of the pile top under the limit state; the greater the strength of the supporting layer, the greater the bearing capacity and the greater the displacement when reaching the limit state; The length of the slipped pile does not affect the bearing capacity of the pile foundation, and the farther the slipping occurs from the bearing layer, the smaller the impact on the bearing capacity *Correspondence to Author: Hongru Li

Shanghai Maritime University, Shanghai 201306, China.

How to cite this article:

Hongru Li. The influence of the stratum structure of the pipe pile sliding pile of the offshore platform. GIobal journal of Mechanical Sciences and Engineering, 2021; 2:6 of the pile foundation. Therefore, in the actual project, attention should be paid to the selection of the bearing layer and the soft soil layer close to the bearing layer should be removed to reduce the impact of the slipping pile on the bearing capacity of the pile foundation and ensure that the bearing capacity of the pile
\end{abstract}




\section{Introduction}

With the rapid development of marine economy, marine engineering has gradually developed into the deep sea. Pile foundation is one of the main types often used in marine engineering. Driven piles in deep-sea foundation structures show the characteristics of increasing pile length and increasing pile diameter. Open steel pipe piles are widely used in marine pile foundation engineering because of their high tensile strength, high compressive strength, strong bending resistance, weak soil squeezing effect, low pile sinking resistance and easy penetration. In the process of large-diameter and super-long pipe piles, a common phenomenon occurs, that is, during the pile driving process, the pile depends only on the weight of the pile hammer when the number of hammers is very small or the number of hammers is zero. The phenomenon of greater penetration depth occurs, which is called pile slipping. The production of slipping piles will have an impact on the safety of pile driving, the quality of the pile foundation, the bearing capacity of the pile foundation and the control of the design height of the pile foundation. It is a major hidden danger in the process of pile sinking. Excessive length of the slide pile will easily cause out-ofcontrol situations such as the breakage of the piling hydraulic pipeline, which brings great safety risks to offshore construction [1]. At the same time, there are relatively few studies on pile sliding problems at home and abroad.

Guo Shengchang et al. ${ }^{[2]}$ described and analyzed the pile slipping problem in the supporting wharf project of the $1 \#$ base of the Hengsha East Beach Fifth Phase Project, which was designed and constructed in the Yangtze River Estuary in 2009. The pile foundation used is $\$ 800 \mathrm{PHC} B$ type pipe pile, the pile length is $47 \mathrm{~m}$, and the maximum slide pile length is $26 \mathrm{~m}$. The main reason for slipping piles is that the upper part of the bearing layer is covered with thick silty soft clay; Li Sa et al. ${ }^{[3]}$ conducted a study on the slipping piles during the installation of the jacket in the East China Sea. The diameter of the pile body is $\oint 2438 \mathrm{~mm}$, the sidewall thickness of the pile is $45 \sim 88 \mathrm{~mm}$, the length of the pile is $118.5 \mathrm{~m}$, and the depth of soil is $96 \mathrm{~m}$. The pile slipping occurs at $24 \mathrm{~m}$ and stops at $62 \mathrm{~m}$, and the length of the pile slipping reaches $38 \mathrm{~m}$. The reason for slipping piles is the existence of a weak soil layer, and three different areas affected by the slipping piles are obtained; Yan Shuwang et al. ${ }^{[4]} \mathrm{de}-$ scribed and studied the pile sliding problem of a jacket platform in the South China Sea, The interval of the sliding pile is $14 \sim 36 \mathrm{~m}$, and the length of the sliding pile is $22 \mathrm{~m}$,based on the energy conservation method, the calculation and analysis method of the slipping range of the super-long and large-diameter pile is established.

Roger Howard et al. ${ }^{[5]}$ conducted on-site pile sinking tests on the San Francisco-Oakland Bridge project. They used 3 open steel pipe piles with a diameter of $2.438 \mathrm{~m}$. Each pile was divided into 4 sections, each with a length of $25.9-30.5 \mathrm{~m}$ and a wall thickness of 40 . $~ 70 \mathrm{~mm}$, the penetration depth is about $95 \mathrm{~m}$.During the piling process, it was found that the slipping phenomenon was found in the first section of the three piles. The surface clay of the first and second piles was thin $(4 \sim 5 \mathrm{~m})$, and the pile slipped about $6 \mathrm{~m}$; the third pile had thicker surface soil (about $20 \mathrm{~m}$ ).), slide the pile about $15 \mathrm{~m}$, and slide the pile $19 \mathrm{~m}$ in the subsequent second section of piling process. The main reason for slipping piles is that there is a thick soft clay layer on the surface of the foundation, and the results of slipping piles are backanalyzed.

To sum up, most of the current researches focus on the judgment of the length of the sliding pile and the influence of the sliding pile on the soil resistance. However, there is a lack of syste- 
matic theoretical research on the influence of stratum structure changes on sliding piles and the impact of sliding piles on the bearing capacity of pile foundations.

\section{Slip pile generation mechanism}

According to the different occurrence time of the sliding piles, the sliding piles can be roughly divided into two types: One is the slipping in the early stage of piling, that is, the initial penetration of the pile under the weight of the pile body or the weight of the pile body plus the weight of the pile hammer, that is, the free depth of soil penetration; The second is the sliding pile that occurred in the process of piling.

In the early stage of piling, the pipe pile penetrates into the soil under the action of pile weight. The pile body must penetrate into the soil to a certain depth before the pile circumference resistance and the pile body weight can reach a balanced state. So that the pile stops sinking. According to the pile weight, hammer weight and soil parameters, the free depth of soil will vary. However, because there is no impact of hammer energy at this time, the free soil depth is easy to predict and generally does not affect the pile driving construction. Therefore, this article mainly analyzes the causes of slipping piles that occur in the process of piling.

Engineering practice experience shows that the slipping during pile driving generally occurs in the following two situations: (1) The surface of the foundation soil is a thicker soft soil layer with a smaller bearing capacity; (2) When the pipe pile penetrates from the harder soil layer to the soil layer with lower bearing capacity. When these two situations occur, the pile tip resistance decreases rapidly when the pile enters the soft soil layer. Although the side resistance area will also increase, the actual side friction resistance is also decreasing due to the increased degree of soil remodeling at the pile-soil interface. At this time, the sum of the pile tip resistance and the side friction resistance of the pile foundation penetrating into the soil is less than the sum of the weight of the pile hammer, which results in the phenomenon of pile slipping. The process of pile sliding is shown in Figure 1-1.

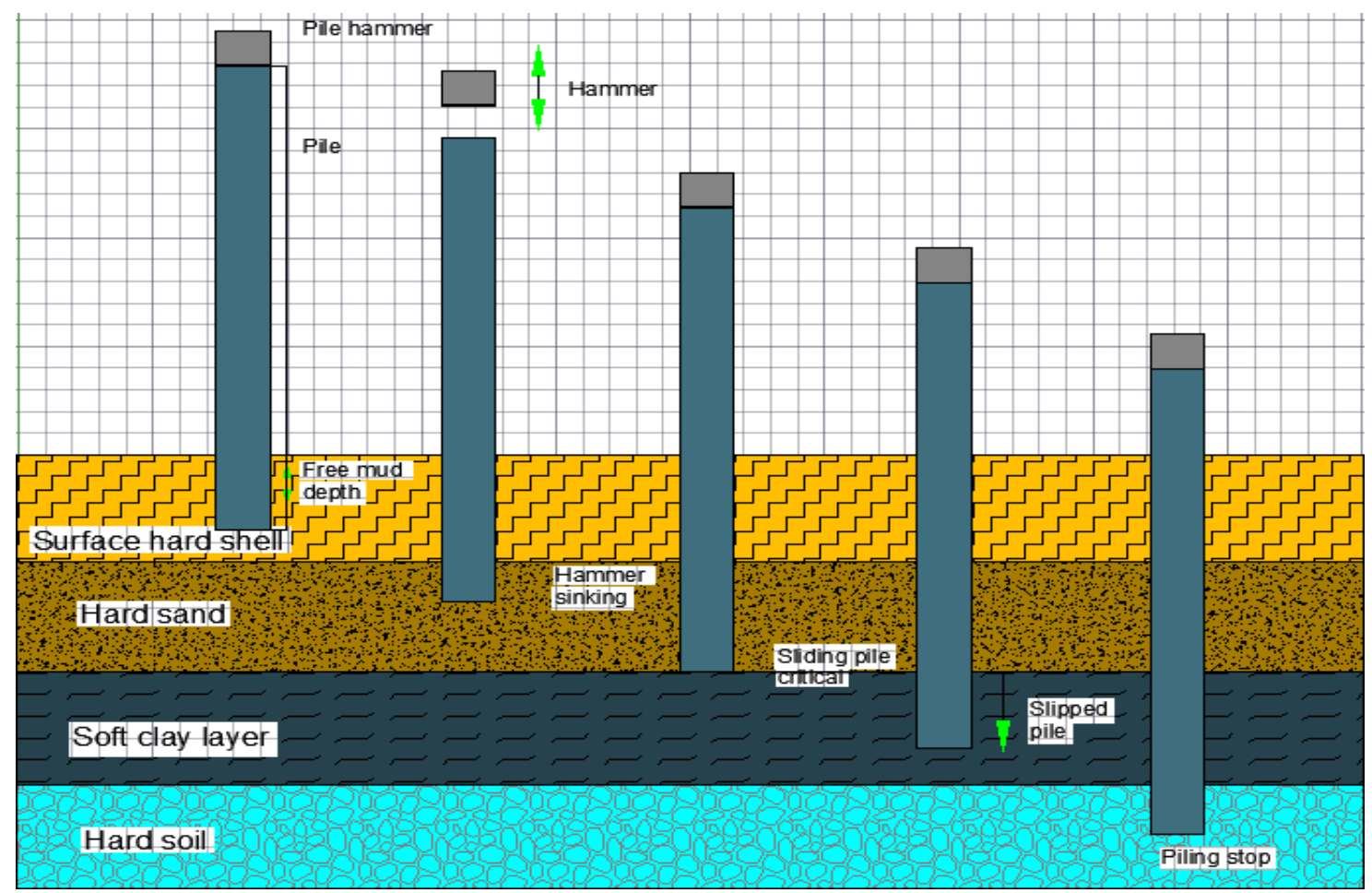

Figure 1-1 Pile sliding process diagram 
Through the analysis of the pile sliding process, the reasons for the pile sliding phenomenon can be predicted from the following points:

(1) There is a thicker soft soil layer in the penetrating soil, and the overlying layer is usually a harder clay layer or sandy soil layer. In the process of pile sinking, due to the hole expansion of the pile and the existence of hammering energy, the soil will generate a large pore water pressure, so that the effective strength of the soil becomes lower. The soil within a certain range of the pile circumference will be disturbed and reshaped to different degrees according to the distance, so that the soil resistance generated during the pile driving process is less than the soil static friction resistance. Comparing sandy soil with cohesive soil, the external friction angle of sandy soil is greater than that of cohesive soil, and its unit frictional resistance will be greater. Especially when the pile penetrates into the sand layer, the pile tip resistance is much greater than the clay layer. At the same time, the sandy soil has strong permeability, the pore pressure generated during the piling process will quickly dissipate in a short time, and the soil strength recovery time is short. In addition, the sandy soil layer will also produce varying degrees of arching effect, which in- creases the friction resistance inside the pile ${ }^{[6]}$. In summary, under the same conditions, the pipe piles need to penetrate the sand layer more hammer strokes than the clay layer, that is, more hammering energy is needed to overcome the resistance. Therefore, when the pile penetrates the harder overburden layer or the sandy soil layer into the softer clay layer, the energy given by the pile hammer remains at the same level, but the pile tip resistance will decrease sharply. Cohesive soil layer provides lower pile side friction resistance, the soil resistance around the pile cannot provide enough support to stop the pile from sinking.
Therefore, under the action of the weight of the pile body and the inertial force generated by the hammering, the penetration depth of the pile body suddenly increases, which exceeds the range of penetration depth that can be controlled by normal construction, and the phenomenon of pile slipping occurs.

(2) Pile weight factor: Through research and comparison, it can be found that the weight of the pile body is one of the important factors affecting the length of the slide pile. The heavier the pile is, the greater the inertial force generated under the same number of hammers, and the greater the soil resistance that the soil needs to provide. For example, two adjacent offshore platforms in the South China Sea have caused pile slipping, and the soil conditions of the two are similar. But one of the platforms has a pile body mass of $375 t$ and a sliding pile length of $10 \sim 30 \mathrm{~m}$. The other platform has a pile mass of $540 \mathrm{t}$ and a sliding pile length of $24 \sim 42 \mathrm{~m}$. The difference in the length of the two piles is large. The greater the mass of the pile, the greater the length of the sliding pile.

(3) Hammering factors: In the process of pile sinking, the greater the depth of the penetration of the pile into the soil, the greater the soil resistance that needs to be overcome. Therefore, the pile hammer is required to provide greater hammer energy as the depth of penetration into the soil increases. But in the process of piling penetration into a certain depth, the hammer energy provided by the single hammer will be maintained at a certain stable level, and the increase of the hammer energy depends on the increase of the number of hammers. When the pile body penetrates the sand layer or other hard soil layer and then enters the clay layer, the unit friction resistance of the soil body decreases, but the hammering energy still maintains the previous level, causing the pile body penetration to increase 
rapidly and slipping occurs.

From the above analysis, it can be seen that the biggest influencing factor of the sliding pile during the piling process is that the sum of the soil resistance provided by the soil is less than the sum of the weight of the pile and the inertial force generated by the pile hammer. If it is possible to make a more accurate prediction of the sliding pile, you can control the energy of the hydraulic hammer in advance. After stabilizing the penetration of the pile body and entering the harder soil layer, gradually increase the click energy of the hydraulic hammer for subsequent conti- nuous piling operations.

It can be known from the foregoing that the sum of soil resistance is the key factor in the production of sliding piles. When the pile enters a certain soil layer, if the total soil resistance is less than the weight of the pile or the sum of the weight of the pile and the hammer or less than the sum of the weight of the pile and the hammer and the inertial force generated by the hammering action, when these three conditions When any one of them appears, that is, when formula 2-3 is satisfied, the phenomenon of pile sliding may occur.

$$
\begin{gathered}
Q_{\mathrm{d}}=Q_{s}+Q_{p}=\mathbf{f}_{s} A_{s}+q A_{p} \\
F=W_{\mathrm{p}}+W_{h} \\
F \geq Q_{\mathrm{d}}
\end{gathered}
$$

In the formula: $\mathrm{f}_{s}$ —Unit pile side resistance, $\mathrm{KN}$

$Q_{\mathrm{d}}$ - The total resistance provided by the soil to the pile, $\mathrm{KN}$

$Q_{s}$ - Total friction resistance of pile side, $\mathrm{KN}$

$Q_{p}$-Total bearing capacity of pile end foundation, $\mathrm{KN}$

$A_{s}$-Outside surface area of pile, $\mathrm{m}^{2}$

$A_{\mathrm{p}}$-Annular foundation area of pile end, $\mathrm{m}^{2}$

$F$ - Total sinking force, $\mathrm{KN}$

$W_{\mathrm{p}}$ - The weight of the pile minus the buoyancy of the pile body, $\mathrm{KN}$

$W_{\mathrm{h}}$-Hydraulic hammer weight, $\mathrm{KN}$

After the pile slip occurs, it generally does not stop in the soft soil layer. If there is a hard soil layer under the soft soil layer, when the pile penetrates this soil layer, the pile tip resistance will increase rapidly, and the speed of the pile in the hard soil layer will gradually decrease. If the

$$
F=Q_{\mathrm{d}}
$$

thickness of the hard soil layer is sufficient, the pile will stop sliding and the speed will become 0 . At this time, the inertial force disappears and further hammering is required to continue penetration. Therefore, the static balance condition is satisfied at the stop of the sliding pile, namely: 
3. Validation of numerical simulation

\subsection{Project overview}

Pile slipping occurred on a platform in the South China Sea ${ }^{[7]}$ during pile sinking. Collect field data of test piles drilled in $\mathrm{BH} 1$ by static cone penetration method. Draw the pile side resistance end resistance curve, and then compare the ABAQUS numerical simulation calculation results.

\subsection{Model building}

Due to the difficulty of directly simulating the entire continuous pile sinking process, and comprehensive consideration of the accuracy of the model and the speed of calculation. We choose to place the pile body into a certain depth of the soil in advance, and then study the pile side resistance and end resistance under static load. A three-dimensional cylinder is used to simulate the soil, and the calculation area is controlled by selecting 30 times the pile diameter in the horizontal direction and preventing the bottom of the pile from touching the bottom in the vertical direction. The pile is a super-long and large-diameter pipe pile. Refer to the above-mentioned engineering example. The pile dia- meter is $2.743 \mathrm{~m}$, the wall thickness is $0.1 \mathrm{~m}$, and the pile length is $158 \mathrm{~m}$. The modified D-P model is selected. Assuming that the pile is an isotropic homogeneous entity, the elastic modulus is $200 \mathrm{GPa}$, the density is $7800 \mathrm{~kg} / \mathrm{m}^{3}$, and the Poisson's ratio is 0.3.The distribution of soil layers and the specific parameters of each soil layer are shown in Table 2-1.

Table 2-1 Engineering parameters of each soil layer

\begin{tabular}{|c|c|c|c|c|c|c|c|}
\hline $\begin{array}{l}\text { Layer } \\
\text { name }\end{array}$ & Soil description & $\begin{array}{c}\text { Layer } \\
\text { thickness } \\
\mathrm{h} / \mathrm{m}\end{array}$ & $\begin{array}{c}\text { Undrained } \\
\text { strength } \\
\mathrm{c} / \mathrm{KPa}\end{array}$ & $\begin{array}{c}\text { External friction } \\
\text { angle } \delta\end{array}$ & $\begin{array}{c}\text { Internal fric- } \\
\text { tion angle } \\
\varphi\end{array}$ & \begin{tabular}{|c} 
Bulk \\
density \\
Y (KN/ \\
$\left.\mathrm{m}^{3}\right)$
\end{tabular} & $\begin{array}{c}\text { Bottom el } \\
\text { evation } \\
H / m\end{array}$ \\
\hline 1 & $\begin{array}{l}\text { Medium-density fine to coarse } \\
\text { sand }\end{array}$ & 2.4 & 0 & 25 & 39 & 8.2 & 2.4 \\
\hline 2 & Soft to hard clay & 8.5 & 22.5 & 0 & 0 & 8.1 & 10.9 \\
\hline 3 & Medium to dense silt & 3 & 0 & 25 & 37 & 8.5 & 13.9 \\
\hline 4 & $\begin{array}{c}\text { Interlayer of medium-dense sandy } \\
\text { silt and hard clay }\end{array}$ & 2.8 & 60 & 0 & 0 & 8.6 & 16.7 \\
\hline 5 & Medium to dense silty fine sand & 3.1 & 0 & 25 & 36 & 8.6 & 19.8 \\
\hline 6 & Hard silt clay & 5.4 & 50 & 0 & 0 & 8.6 & 25.2 \\
\hline 7 & Dense silt and fine silt & 14.8 & 0 & 30 & 39 & 8.6 & 40 \\
\hline 8 & $\begin{array}{l}\text { Interlayer of hard silty clay and } \\
\text { fine silt sand }\end{array}$ & 16.8 & 60 & 0 & 0 & 8.3 & 56.8 \\
\hline 9 & $\begin{array}{l}\text { Interlayer of hard silty clay and } \\
\text { fine silt sand }\end{array}$ & 5.1 & 140 & 0 & 0 & 9.3 & 61.9 \\
\hline 10 & Medium-dense sandy silt & 2.8 & 0 & 25 & 36 & 8.3 & 64.7 \\
\hline 11 & Hard silty clay & 6.2 & 95 & 0 & 0 & 8.8 & 70.9 \\
\hline 12 & Hard silty clay & 4.6 & 145 & 0 & 0 & 8.8 & 75.5 \\
\hline 13 & Medium density silt & 4.3 & 0 & 25 & 36 & 8.7 & 79.8 \\
\hline 14 & Hard clay & 10.9 & 85 & 0 & 0 & 8.8 & 90.7 \\
\hline 15 & Very hard clay & 22.1 & 130 & 0 & 0 & 8.9 & 112.8 \\
\hline
\end{tabular}


Hongru Li, GJMSE, 2021; 2:6

\begin{tabular}{|c|c|c|c|c|c|c|c|}
\hline 16 & Hard clay & 6.2 & 140 & 0 & 0 & 9.4 & 119 \\
\hline 17 & Hard clay & 12.6 & 190 & 0 & 0 & 9.3 & 131.6 \\
\hline 18 & Dense powder to medium sand & 38.8 & 0 & 35 & 40 & 9.7 & 170.4 \\
\hline
\end{tabular}

The pile body and the soil around the pile are in contact with each other by surface to surface. Apply binding constraints to the bottom of the pile end and the soil at the end of the pile so that the pile end and the soil do not separate. The interaction between the pile body and the soil body adopts the method of hard friction contact. When meshing the soil, adopt the method of middle density and outer sparse, top density and lower sparse. When meshing the soil, adopt the method of middle density and outer sparse, top density and lower sparse. The boundary conditions are set to impose horizontal constraints around the soil and vertical constraints at the bottom of the soil to ensure the stability of the soil. The overall grid division and constraints are shown in Figure 2-1 and 2-2.

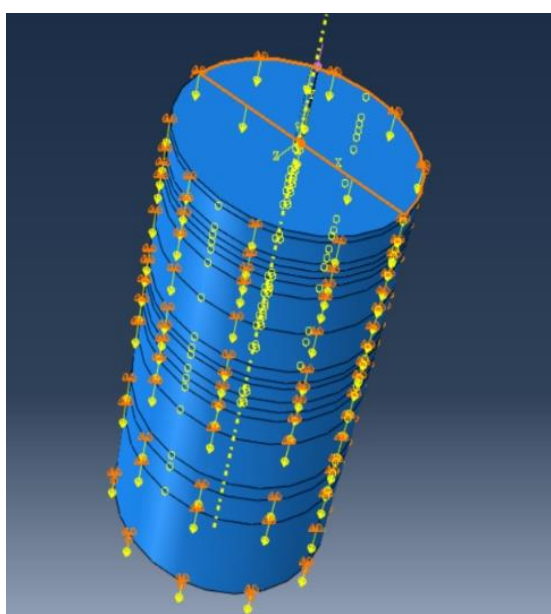

Figure 2-2 Model constraints

\subsection{Comparative Results}

The stress cloud diagram of the pile body is shown in Figure 2-3. From the comparison between the numerical simulation results in Figure 2-4 and the field test records, we can know that the change trends of the two are basically the

same. When the soil layer changes, the value will also change significantly. The calculation results are basically consistent, so the construction can be judged. The selection of model method and constitutive model is reasonable and feasible.

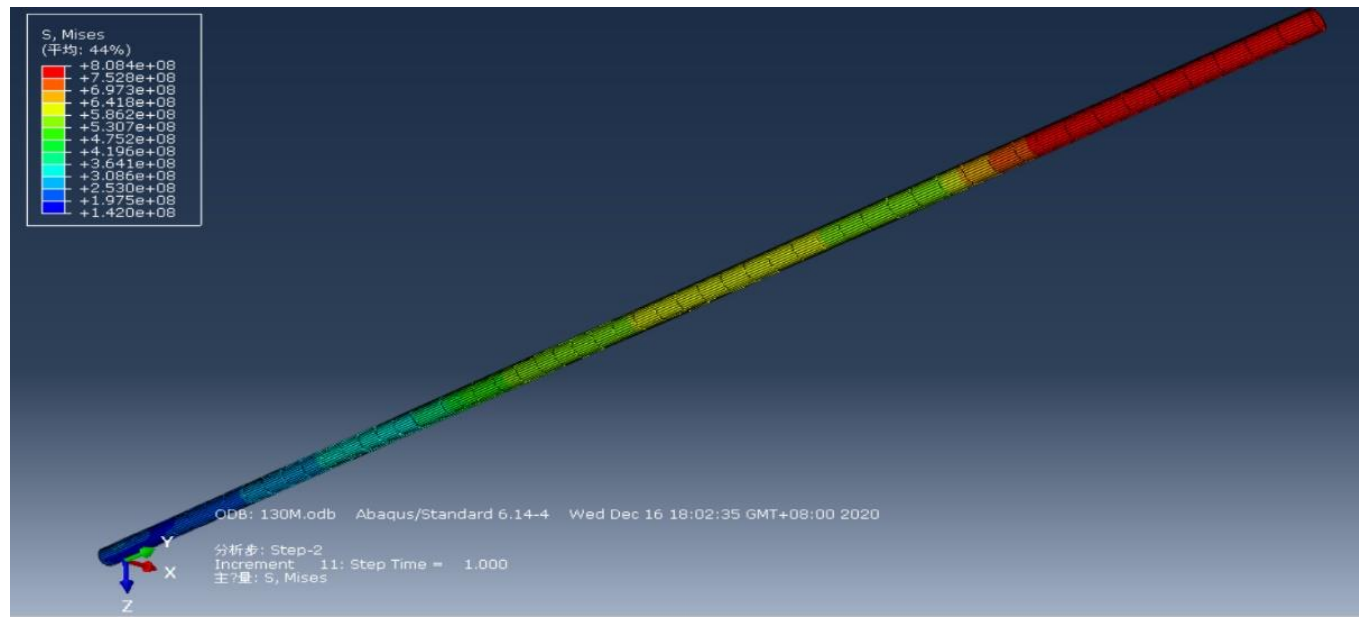

Figure 2-3 Stress cloud diagram of pile body 


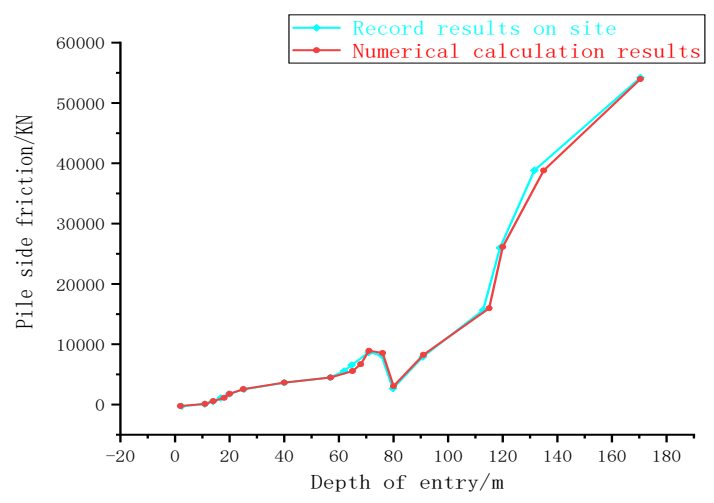

Figure 2-4 Comparison of pile side resistance results

4. The influence of slipping pile on the bearing capacity of pile foundation

Based on the collected field test data, the piles of two adjacent sites are selected. The lengths of the two piles are $117.6 \mathrm{~m}$ and $101.5 \mathrm{~m}$ respectively, and the final depths of mud pene- tration are $96.0 \mathrm{~m}$ and $89.7 \mathrm{~m}$ respectively. The basic parameters of the soil layer distribution and the end resistance of each soil layer are shown in Table 3-1. The bearing capacity of the two piles calculated using API specifications is basically the same, and the soil distribution, pile length and mud depth are basically the same. The biggest difference is that pile \#1 has slipped while pile \#2 has not slipped.

Table 3-2 Two-pile soil layer and pile end resistance and lateral resistance distribution

\begin{tabular}{|c|c|c|c|c|c|c|}
\hline \multirow{2}{*}{\multicolumn{2}{|c|}{$\begin{array}{l}\text { Layer } \\
\text { name }\end{array}$}} & \multirow[b]{3}{*}{ Medium-compact silty fine sand and clay sand } & \multicolumn{2}{|c|}{ depth } & \multirow{2}{*}{$\begin{array}{c}\text { Side friction } \\
\qquad / \mathrm{kpa}\end{array}$} & \multirow{2}{*}{$\begin{array}{l}\text { Unit terminal resistance } \\
\qquad / \mathrm{Mpa}\end{array}$} \\
\hline & & & \multirow{2}{*}{\begin{tabular}{c|} 
unit/m \\
0.0
\end{tabular}} & \multirow{2}{*}{$\begin{array}{c}\text { Bottom } \\
\text { layer/m } \\
1.8\end{array}$} & & \\
\hline \multirow{15}{*}{ pile\#1 } & 1 & & & & 2 & 0.07 \\
\hline & 2 & Medium to dense fine sand & 1.8 & 3.3 & 7 & 0.28 \\
\hline & 3 & $\begin{array}{l}\text { Laminated layer of soft silty clay, sandy silt, and } \\
\qquad \text { silt fine sand }\end{array}$ & 3.3 & 8.0 & 11 & 0.13 \\
\hline & 4 & Soft to slightly hard silty clay & 8.0 & 13.0 & 22 & 0.20 \\
\hline & 5 & Medium-compact silty fine sand & 13.0 & 19.5 & 40 & 1.62 \\
\hline & 6 & Dense silty fine sand & 19.5 & 24.4 & 70 & 3.76 \\
\hline & 7 & Medium-dense sandy silt and fine sand & 24.4 & 32.0 & 64 & 2.72 \\
\hline & 8 & Slightly hard to hard silty clay & 32.0 & 39.2 & 63 & 0.57 \\
\hline & 9 & Very hard silty clay silt stack & 39.2 & 53.0 & 67 & 0.99 \\
\hline & 10 & Medium to dense sandy silt and fine sand & 53.0 & 55.2 & 81 & 4.80 \\
\hline & 11 & Hard silty clay & 55.2 & 57.6 & 156 & 1.80 \\
\hline & 12 & Medium to dense sandy silt and fine sand & 57.6 & 64.2 & 81 & 4.80 \\
\hline & 13 & Very hard silty clay silt stack & 64.2 & 72.8 & 67 & 1.08 \\
\hline & 14 & Medium to dense sandy silt & 72.8 & 81.0 & 81 & 4.80 \\
\hline & 15 & Very hard to hard silty clay & 81.0 & 125.0 & 170 & 1.43 \\
\hline pile\#2 & 1 & Medium to dense fine sand and silty fine sand & $0.0,4.0$ & $4.0,19.5$ & 5,41 & $0.21,2.45$ \\
\hline
\end{tabular}


Hongru Li, GJMSE, 2021; 2:6

\begin{tabular}{|c|c|c|c|c|c|c|}
\hline 2 & Medium-dense sandy silt & 19.5 & 24.0 & 57 & 2.36 \\
\hline 3 & Dense fine sand & 24.0 & 41.0 & 96 & 9.2 \\
\hline 4 & Very hard silty clay & 41.0 & 44.2 & 101 & 0.99 \\
\hline 5 & Medium to dense silty fine sand & 44.2 & 57.0 & 89 & 7.2 \\
\hline 6 & Very hard silty clay & 57.0 & 94.0 & 140 & 1.26 \\
\hline 7 & Medium to dense silty fine sand & 94.0 & 104.1 & 81 & 4.8 \\
\hline 8 & Medium-dense sandy silt & 104.1 & 109.5 & 67 & 2.9 \\
\hline
\end{tabular}

Pile \#1 has a slipping pile of $38 \mathrm{~m}$ in length at $24 \mathrm{~m}$ and stops at $62 \mathrm{~m}$. The unit pile tip resistance and unit pile side resistance were obtained through the soil resistance calculation formula recommended by the API specification, and compared with the field test data, as shown in Figures 3-1, 3-2 and 3-3. It is not difficult to find that the field test data is slightly smaller than the standard calculation value before $24 \mathrm{~m}$, that is, before the pile slip occurs. This is because the selection of parameters in the API specification formula is safe and conservative, which is beneficial to the stability and reliability of the pile foundation, but it will have an adverse effect on the analysis of the sliding pile; After $24 \mathrm{~m}$, that is, after the sliding pile occurred, the unit lateral resistance has been significantly reduced, which is much smaller than the value calculated in the specification, and its distribution has also changed. It shows that the generation of slipped piles has a great influence on the side resistance of piles. The reason is that in the process of pile sinking, the relative displacement between the pile and the soil caused by the mud skin generated around the pile causes excessive plastic sliding, and the pile-soil interface be- comes smoother under the penetrating move- ment of the pile. The soil around the pile is affected by many factors, including soil squeezing and excessive pore water pressure. At the same time, there is a certain strain softening characteristic, and the strength of the soil is reduced, which causes a significant reduction in the side friction resistance of the pile. For the pile tip resistance, the impact of the sliding pile is not very large compared to the pile side friction resistance, and the general trend of the graph has not changed. This is because the soil at the end of the pile is less disturbed and the degree of reshaping is not high, which can provide sufficient soil resistance. On the whole, the impact of the sliding pile on the bearing capacity of the pile foundation mainly comes from the reduction of the pile side resistance. The unit pile side resistance will be reduced by about 6-10 times, while the impact on the pile tip resistance is small.

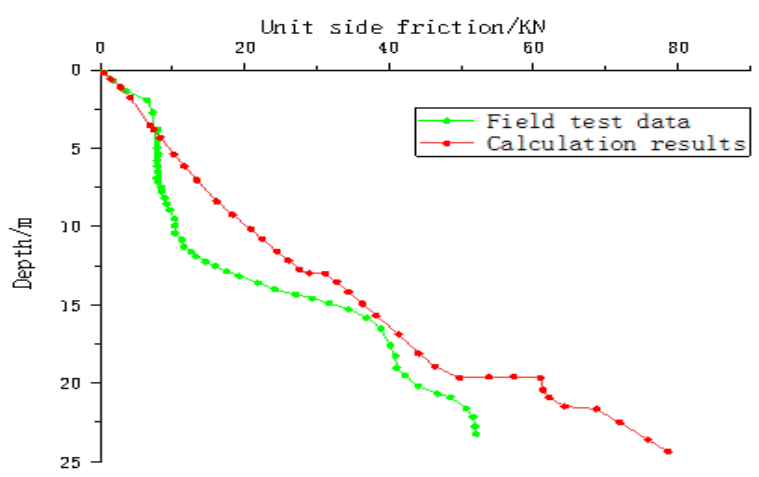

Figure 3-1 Comparison of unit side resistance when the pile is not slipped 


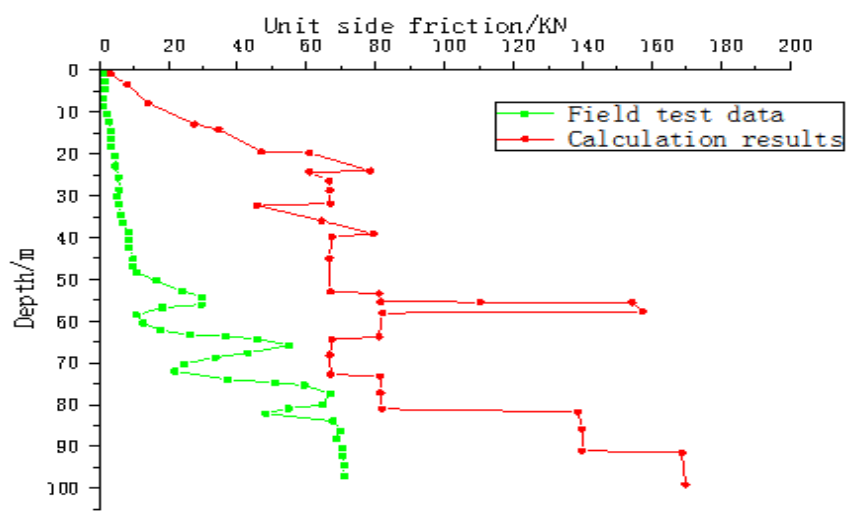

Figure 3-2 Comparison of unit side resistance after sliding piles

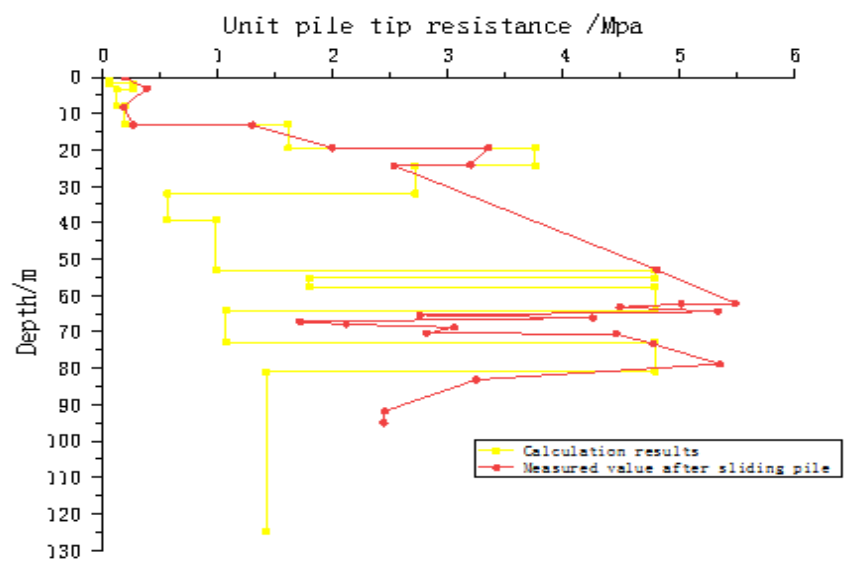

Figure 3-3 Comparison of unit pile tip resistance after slipping pile generation

\section{Numerical simulation study of changing} stratum structure

Offshore platform pipe piles often encounter different and complex stratum structures during the pile-sinking process, generally showing a stratum structure with upper soft and lower hard, but they may also encounter soft and hard alternate or upper hard and lower soft stratum structures. There is a high probability that the pile will slip. Numerical simulation is carried out for special stratum structure conditions, and the deforma- tion and force characteristics of pipe piles when the stratum structure changes are studied and analyzed, so as to provide reference for reducing the occurrence of pile sliding and carrying out engineering control.

Three soil layers, soft soil layer, strong soil layer and general soil layer are selected as representatives. The soil parameters of each type of soil are shown in Table 4-1, and the pile parameters are shown in Table 4-2.

Table 4-1 Soil physical parameters

\begin{tabular}{|c|c|c|c|c|c|}
\hline Soil layer name & $\begin{array}{c}\text { Bulk density } \\
\left(\mathrm{kg} / \mathrm{m}^{3}\right)\end{array}$ & $\begin{array}{c}\text { Elastic Modulus } \mathrm{E} \\
(\mathrm{Mpa})\end{array}$ & $\begin{array}{c}\text { Poisson's ra- } \\
\text { tio } \mu\end{array}$ & $\begin{array}{c}\text { Cohesion } \\
(\mathrm{Kpa})\end{array}$ & $\begin{array}{c}\text { Internal friction } \\
\text { angle } \varphi\end{array}$ \\
\hline Soft soil & 17.5 & 5 & 0.4 & 15 & 12 \\
\hline Strong soil & 18.5 & 50 & 0.35 & 30 & 18 \\
\hline General soil layer & 19.3 & 58 & 0.36 & 26 & 24 \\
\hline
\end{tabular}

Table 4-2 Physical parameters of pile

Pile length $\mathrm{L} / \mathrm{m}$

Outer diameter

Poisson's ratio $\mu$

Elastic Modulus E

$$
\mathrm{D} / \mathrm{m}
$$

(Gpa)

0.3

Pile end wall thickness $t / m$

\section{0}

210

0.1 
(1) Change the position of the soft soil layer Taking the four layers of soil as a whole, the positions of the soft soil layers are placed in four parts, including the upper part, the middle upper part, the middle lower part, and the lower part, corresponding to the four working conditions. The numerical simulation study is carried out on each working condition. The layout of the soft soil layer under various working conditions is shown in Figure 4-1.

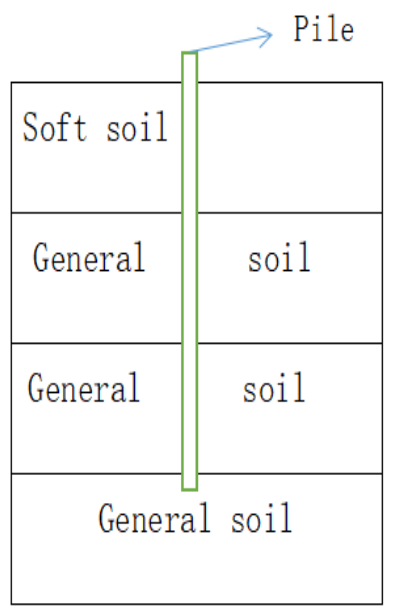

Working I

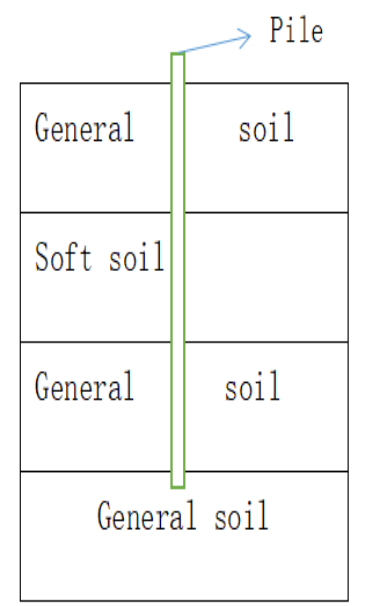

Working II

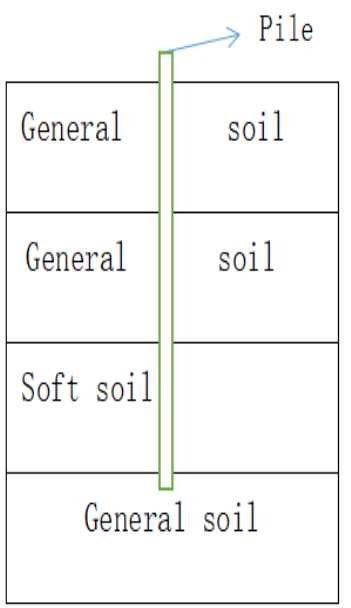

Working III

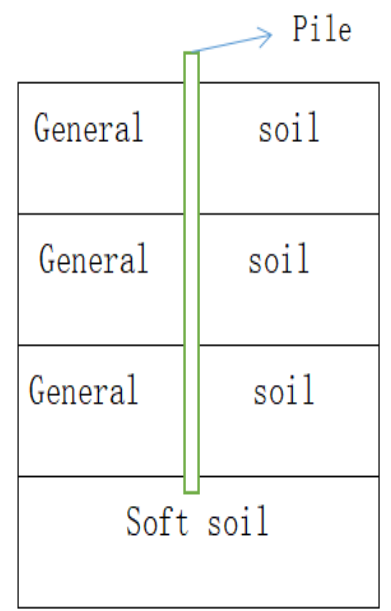

Working IV

Figure 4-1 The distribution of soft soil layers under various working conditions

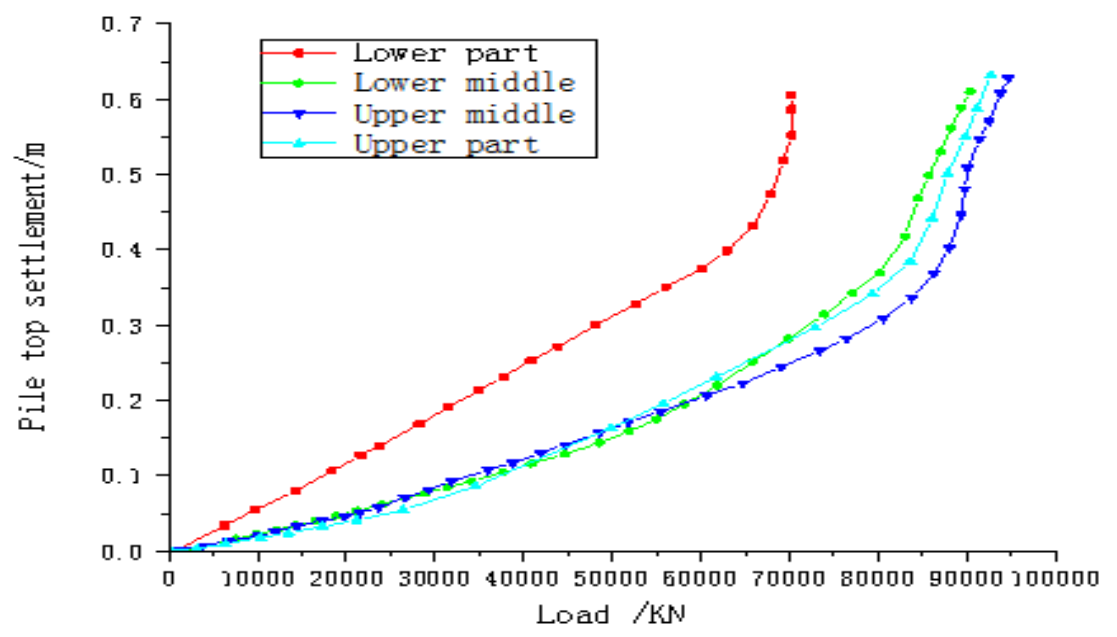

Figure 4-2 Q-S curve after soft soil layer change

Analyze the Q-S curve obtained after changing the position of the soft soil layer, as shown in Figure 4-2.It can be found that when the soft soil layer is located in the middle and upper part of the four-layer soil, the pile foundation has the best bearing performance, and the amount of settlement generated under the same load is the smallest. When the displacement reaches $0.4 \mathrm{~m}$, the settlement change of the pile body has a significant increase with the increase of the load, indicating that the pile body has reached the state of ultimate bearing capacity. Under the same conditions, the ultimate bearing capacity is the largest when the soft soil layer is located in the upper middle part; On the contrary, when the position of the soft soil layer is at the bottom of the pile body as the bearing layer, the pile body has the smallest bearing capacity. The reason may be that the pile end resistance provided by the soft soil layer is small, which affects the bearing capacity of the pile foundation. In condition IV, the load that the pile can withstand when the same settlement occurs is the smallest, indicating that the soft soil layer as a bearing layer will increase the settlement of the pile foundation, even exceeding the designed pile sinking depth, 
which affects the normal progress of the project. Analyzing the Q-S curve as a whole, it can also be found that the changing trends of working conditions II, III and IV are roughly the same in the four working conditions. And working condition I, that is, the curve of the soft soil layer as the bottom bearing layer has obvious stratification with the other three curves, indicating that the position of the soft soil layer has the greatest influence on whether it is located in the bearing layer or not. When the soft soil layer is distributed above the bearing layer, the degree of influence of different positions on the bearing capacity of the pile foundation is basically the same, only slightly different in value, and its changing trend is basically unchanged. When the soft soil layer is located in the bearing layer, it has a significant impact on the bearing capacity of the pile foundation. The load with the same settlement amount is only about $50 \%$ of the other working conditions. At the same time, the settlements corresponding to the inflection points of the four curves are basically the same, and roughly all occur at the position where the settlement is $0.4 \mathrm{~m}$. After that, the displacement rises linearly, indicating that the pile is damaged. The inflection point is roughly the same, indicating that the different position distribution of the soft soil layer does not affect the displacement of the pile when it reaches the ultimate bearing capacity.

Combined with the conditions of the pile sliding, the first type of pile sliding occurs when the soft soil layer is on the surface, that is, the free mud depth. At this time, the bearing capacity of the pile foundation is slightly greater than the pile sliding near the supporting layer, that is, working condition III. It may be caused by the timeliness of the bearing capacity of the pile foundation and insufficient exertion of the pile side friction. Comparing working condition II and working condition III, it is found that the bearing capacity of the pile foundation is lower when the sliding pile occurs close to the bearing layer, indicating that the influence of the sliding pile on the bearing capacity is from near to far. The reason is that the soil layer is reshaped due to the slipping pile, and the strength is reduced, which cannot provide enough soil resistance. The next soil layer of the soil layer where the pile slip occurs requires a certain distance to provide sufficient soil resistance to stop the pile slip. When the distance is sufficient, the pile slip does not have a direct impact on the subsequent soil layer.

In summary, changing the location of the soft soil layer will have an impact on the bearing capacity of pipe piles, especially when used as a bearing layer, the impact is more significant. But it has little effect on the settlement of the pile top and hardly changes the displacement of the limit state.

(2) Interval distribution of soft soil layer and strong soil layer

Similarly, four layers of soil are selected as a whole, and the soft soil layer and the strong soil layer are distributed at intervals, and this kind of more complicated stratum structure changes are analyzed through numerical simulation. The specific soil layer distribution of each working condition is shown in Figure 4-3.

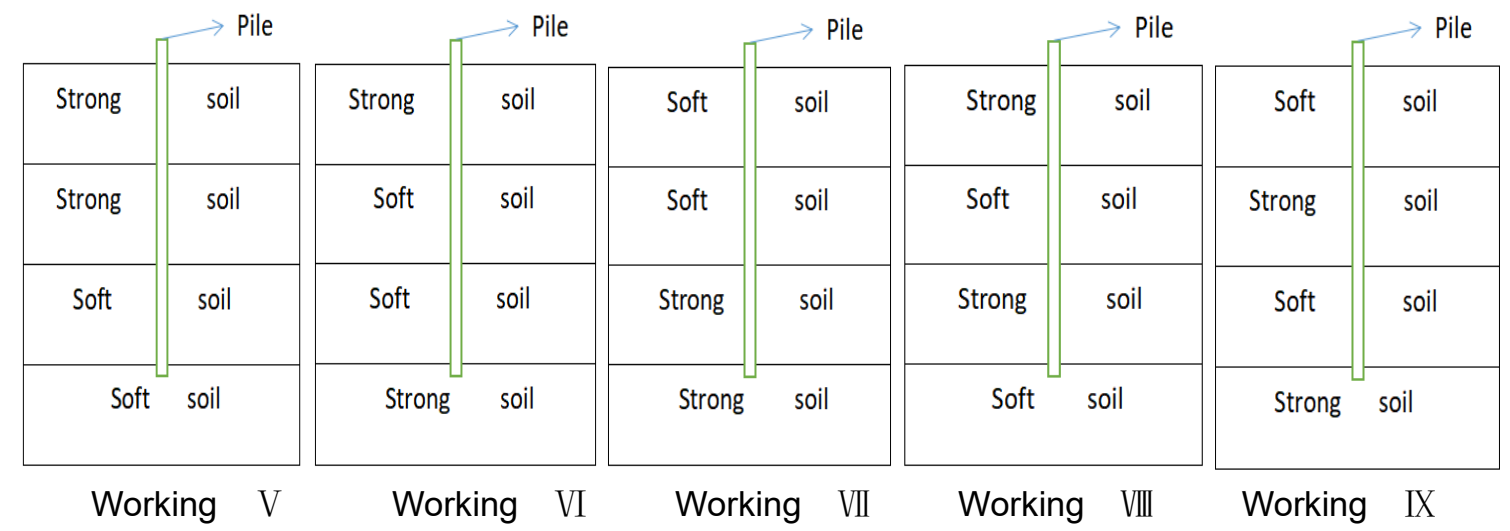

Figure 4-3 Distribution of soft and hard soil layers under various working conditions 


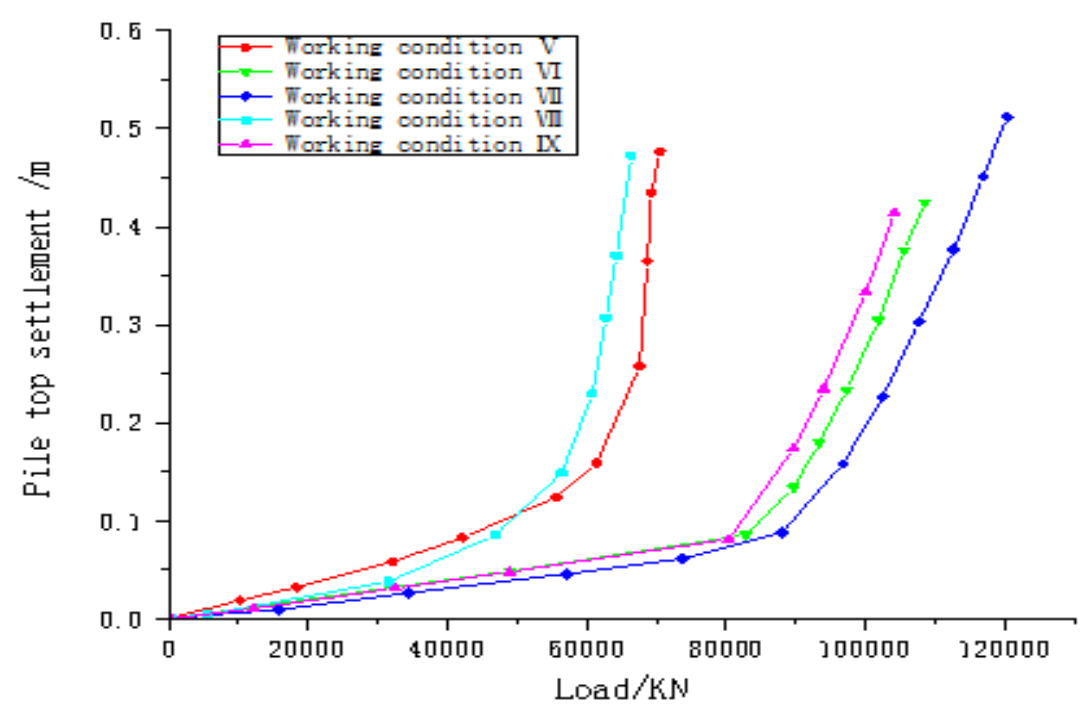

Figure 4-4 Comparison of Q-S curves in different intervals

Analyze the comparison of Q-S curves in different intervals, as shown in Figure 4-4. It can be found that the pile has the best bearing capacity under working condition seven, and the load that can be withstood is the largest when the same pile top settlement is produced; The opposite is working condition VII, its ultimate bearing capacity is the worst in each working condition, when the load is the same, the pile top settlement is the largest. At the same time, it can be clearly found that there is an obvious grouping phenomenon. The working condition $\mathrm{V}$ and working condition VIII in which the soft soil layer is used as the supporting layer are regarded as a group. Their bearing capacity is worse than other working conditions. The commonality is that the soft soil layer is used as the last layer. Working condition VI, working condition VII and working condition IX as a group, this group has better loadbearing capacity and has obvious advantages compared with the previous group. The changing trends of the working conditions between the two groups are basically the same, with little difference. At the same time, comparing the working condition VII with the previous working condition I, it can be found that the comparative analysis of working condition 7 and working condition 9 shows that the first type of pile slipping occurs at most in working condition VII, and working condition IX can be in the third layer of soil. Pile slipping occurs, but the bearing capacity of working condition VII is obviously better than that of working condition IX. It shows that the occurrence of free mud entry, that is, the occurrence of the first type of slipping piles has less impact on the pile foundation than the impact of slipping piles on the piles when the strong soil layer penetrates into the soft soil layer. Comparing working condition $\mathrm{VI}$ and working condition IX, it is shown that the length of slipping pile has no direct influence on the bearing capacity of pile foundation. The bearing capacity of working condition VI is greater than that of working condition IX because the position of the slipping pile occurs earlier than that of working condition IX, which exerts influence on the pile end the impact of layer is also less than working condition IX.

To sum up, in the engineering practice of the pile sinking process of offshore platform pipe piles, the soil layer with strong bearing characteristics and strong soil strength should be selected as the bearing layer as much as possible. Give full play to the bearing capacity of the pile foundation as much as possible and produce a smaller displacement under the same load. At the same time, it is necessary to remove the weak soil layer closer to the bearing layer to reduce the impact of the slipping pile on the bearing capacity of the pile foundation and ensure that the bearing capacity of the pile foundation meets the design requirements. 


\section{Conclusion}

(1) Sliding piles will reduce the bearing capacity of the pile foundation, and the main factor leading to the reduction of the bearing capacity of the pile foundation is the reduction of the pile side friction resistance. This is because during the process of pile sinking, plastic sliding will occur after the sliding of the pile, and the pile-soil interface will become smoother under the penetration movement of the pile. The soil around the pile is affected by many factors, including soil squeezing and the generation of excessive pore water pressure also has certain characteristics of strain softening, which reduces the strength of the soil, which in turn causes the pile side friction resistance to be significantly reduced.

(2) Changing the position distribution of the soft soil layer will have an impact on the bearing capacity of pipe piles, especially when used as a bearing layer, the impact is more significant. But it has little effect on the settlement of the pile top and hardly changes the displacement of the limit state.

(3) The impact of the sliding pile on the bearing capacity of the pile is from near to far. The reason is that the soil layer of the sliding pile is remodeled, and the strength is reduced, and it cannot provide enough soil resistance. The next soil caused by the sliding pile the layer needs a certain distance to provide enough soil resistance to stop the sliding pile. When the distance is sufficient, the sliding pile does not have a direct impact on the subsequent soil layer.

(4) The different distribution of strong and weak soil layers will affect the bearing capacity of the pile foundation, especially the type of soil in the supporting layer. When the other conditions are the same, the greater the strength of the bearing layer, the greater the ultimate bearing capacity and the smaller the pile top settlement when the ultimate bearing state is reached.

(5) The length of the sliding pile has no direct effect on the bearing capacity of the pile foundation, and the location of the sliding pile will have an influence on the bearing capacity of the pile foundation. Therefore, in actual engineering, the soft soil layer close to the bearing layer needs to be treated to ensure that the bearing capacity of the pile foundation meets the design requirements.

\section{References}

[1] Yin Hanjun, Liu Yuxi, Zhang Xiaowei. A New Method for Calculating Sliding Length of Large Diameter and Super Long Steel Pile[J]. China Offshore Oil, 2014, 26(SI): 35-38

[2] Guo Shengchang, Wu Shaolin.Analysis and Solution of Pile Sliding Problem in Pile Sinking Construction[J]. Water transport engineering, 2011(12): 163-166

[3] Li Sa, Wuxingzhou, Wang Yaocun.Research on Soil Resistance Considering the Influence of Sliding Pile in the Process of Pile Driving[J]. Chinese Journal of Geotechnical Engineering, 2015 (06): 1150-1157

[4] Yan Shuwang, Chen Hao, Jia Zuolin.Analysis of Sliding Problem of Large Diameter and Super Long Steel Pipe Pile Based on Capacity Method[J]. Marine Engineering, 2016(05): 63-71

[5] A. R. Dover, J. Davidson. Large Diameter Steel Pipe Piles Running Under Self Weight In Soft Clay-Predicted VS. Observed Behavior-Richmond-San Rafael Bridge Seismic Retrofit. 11th Triennial International Conference on Ports San Diego, California, United States, 2007.1 10

[6] Dong Wei, Research on Analysis Method of Large Diameter and Super Long Pile Dynamic Pile Driving of Offshore Oil Platform[D]. Tianjin; Tianjin University, 2009

[7] Yan Shuwang, Jia Zuolin, Sun Liqiang. Research on Mechanism and Calculation Method of Sliding Large Diameter and Super Long Steel Pipe Piles[J]. Engineering mechanics, 2015(09): 158164

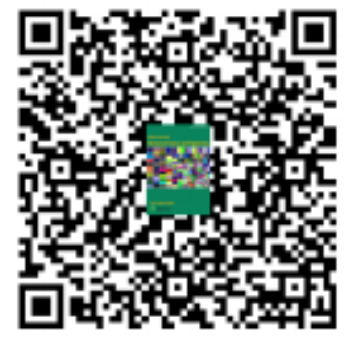

